\title{
Clinical complaints and their handling: a time for change?
}

Northern Regional Newcastle upon Tyne NE6 4PY

Liam J Donaldson, regional director of public health

Julie Cavanagh, senior registrar in public health medicine

Correspondence to: Professor Donaldson Accepted for publication 8 November 1991.

Liam J Donaldson, Julie Cavanagh

\begin{abstract}
Objectives - To assess the performance of the hospital complaints procedure for complaints proceeding to peer review and the quality of responses to complainants.

Design - Retrospective study of data on clinical complaints proceeding to peer review during 1986-91 from clinical records, correspondence, reports of the complaints investigations, and expert review of written responses to complainants.
\end{abstract}

Setting - Northern Regional Health Authority, covering three million people.

Subjects - All 71 clinical complaints investigated to the third stage of the hospital complaints procedure and a sample of 65 written responses to complainants.

Main measures - Characteristics, duration, and outcome of complaints; findings of peer review; and quality of written responses at various stages in the procedure as evaluated by an expert panel against eight agreed criteria.

Results - The median duration of a complaint investigated through all stages of the procedure was 381 days. The longest median stages were those involving attempted resolution locally (131 days) and in which peer review was being arranged (113 days). More complaints alleging failure of communication were upheld by peer review $(46 / 59,78 \%)$ than those alleging misapplication of clinical skills (20/98, $20 \%$ ) or failure to initiate appropriate investigations or treatment $(8 / 32,25 \%)$. Written responses commonly fell below the standards agreed by the expert panel.

Conclusions - The hospital complaints procedure takes too long and its final peer review stage may not demonstrate sufficient impartiality. The written responses suggest that criticism is not welcomed as a way of improving service.

Implication - The clinical complaints procedure needs to be reformed to ensure true accountability to patients.

\section{Introduction}

The Citizen's Charter introduced mechanisms to make providers of public services more accountable to their users. An important element of such a process of accountability is an effective system for investigating and resolving complaints, and this is an issue which is emphasised within the Patient's Charter. ${ }^{23}$

The present hospital complaints procedure was introduced in $1981^{4}$ and revised after the Hospital Complaints Procedure Act in 1985. Further explanatory guidance was issued in $1988 .^{6}$ The procedure comprises three stages, the last of which involves an independent peer review of complaints concerning the exercise of clinical judgement. The procedure has been criticised by the Association of Community Health Councils on the grounds that it is lengthy and not guaranteed to be impartial and that explanations given are not sufficiently comprehensive. ${ }^{7}$ Allegations of bad practice in the handling of complaints by health authorities comprised about a sixth of the workload of the health service commissioner. $^{8}$

We analysed all clinical complaints which entered the peer review phase of the complaints procedure over a five year period in one health region and examined the quality of responses made to complainants. The adequacy and appropriateness of the present clinical complaints procedure are reviewed in the light of our findings.

\section{Methods}

The study was carried out in Northern region, one of the 14 English health regions, which comprises about three million people. It included 71 clinical complaints referred to the regional director of public health and investigated to their conclusion under the hospital complaints procedure during the five year period ending in July 1991.

\section{CLINICAL COMPLAINTS PROCEDURE}

The hospital complaints procedure is set out in a health circular ${ }^{4,6}$ and can entail three stages. The procedure to be followed in a complaint involving the exercise of clinical judgement by a hospital doctor or dentist came into existence after consultation with the profession, as an annex to the circular of $1981,{ }^{4}$ and has remained largely unaltered. In the first stage emphasis is placed on prompt and effective resolution of a complaint at local level. When the complaint concerns clinical matters the consultant is asked to meet the complainant to try to resolve the complaint by discussion. This stage is usually concluded with a letter of explanation written by the hospital or district manager with the advice of the consultant. If the patient is dissatisfied with this response he or she can ask for the complaint to be referred to the regional 
director of public health (stage two of the procedure), whose role is to decide whether the complaint concerns clinical judgement, whether it is substantial in nature, and whether it is likely to be the subject of litigation (if so it should not be investigated further).

Based on assessment of the circumstances, the regional director of public health can refer the complaint to stage three of the procedure, which involves a peer review, organised in consultation with the Joint Consultants Committee. Two independent consultants in appropriate specialties from outside the region concerned are appointed to investigate the complaint. They visit to review the patient's clinical records as well as to meet the complainant, the consultant in charge of the case, and any other relevant staff. The independent consultants provide a report to the regional director of public health, who then conveys the findings to the hospital or district health authority manager. In turn, the manager writes to the complainant. There is no appeal mechanism, and though the health services commissioner can (and does) investigate the administration of the complaints procedure, he is prohibited from examining the substance of clinical complaints themselves.

GATHERING DATA ON CLINICAL COMPLAINTS In the first part of the study the following data on each patient were extracted from the clinical records, the letters of complaint and response, and the reports of the investigation of the complaints: sex, date of birth, district and speciality of treatment, date of initiation of each stage of the complaints procedure (and of the main steps within them), nature of the complaint(s), who brought the complaint(s), and whether the complaint(s) were substantiated by peer review. Almost all of the independent consultants' reports clearly indicated whether they considered that the complaints were justified; if this was not clear we made no judgement. Neither the patient's nor the consultant's identification details were extracted, to preserve anonymity.

Data collection was retrospective, covering complaints in which the procedure had already been concluded. The handling of the complaint was therefore not affected by the knowledge that it was the subject of an evaluation (the Hawthorne effect ${ }^{9}$ ).

EVALUATION OF RESPONSES TO COMPLAINANTS The second part of the study entailed evaluating the quality of written responses made to the complainants at the various stages of the complaints procedure and covered a sample of 10 complaints drawn randomly and 65 associated letters to complainants.

The responses were evaluated by a three person panel with professional expertise in communications and consumer affairs and included the director of communications of a health authority, a community health council secretary, and a senior consumer advice officer.
After becoming familiar with the hospital complaints procedure the panel discussed the documentation relating to a small sample of complaints and then used this as well as general experience to agree eight characteristics which would be the basis for a qualitative assessment of the responses to complaints. The characteristics were whether the response was personalised, comprehensive in addressing all the points of complaint, and expressed in a sympathetic or apologetic tone and whether it provided an intelligible explanation; showed a commitment or intention to investigate the complaints or to act on the results of the investigation; suggested impartiality of the respondent and his health authority; and offered practical support. The panel agreed that all eight characteristics should be evident in responses made at the first and third stages of the procedure. It was decided, however, that as the regional director of public health had no direct role in addressing the points of a complaint or providing an explanation, responses at the second stage of the procedure would not be assessed for these characteristics. Each characteristic (when appropriate within the 65 responses) was rated on a five point categorical scale by each panel member, with the lowest rating indicating poor quality and the highest rating high quality.

\section{Results}

Of the 71 patients who were involved in the complaints, 34 were men and 37 were women; their median age was 55 . Their complaints related to a main consultant in a specialty as follows: surgical (32, 45\%); medical (19, $27 \%)$; obstetrics and gynaecology (9, 13\%); psychiatry $(5,7 \%)$; and paediatrics $(6,8 \%)$. Overall, $28(39 \%)$ complaints were brought by the patients, $21(30 \%)$ by their spouse, and $22(31 \%)$ by someone else (usually another relative). In $37(52 \%)$ cases the complainant was assisted in bringing the complaint by the secretary of the Community Health Council.

The median time taken to complete the complaints procedure was 381 days, with the longest phases overall being those in which local resolution of the complaint was being

Table 1 Duration of clinical complaints which progressed through all stages of procedure

\begin{tabular}{|c|c|c|}
\hline & \multicolumn{2}{|c|}{ Duration (days) } \\
\hline & Median & $\begin{array}{c}\text { Interquartile } \\
\text { range }\end{array}$ \\
\hline $\begin{array}{l}\text { Stage } 1 \text { (local): } \\
\text { District tries to resolve complaint } \\
\text { locally before referring to Stage } 2\end{array}$ & 131 & $79-254$ \\
\hline $\begin{array}{l}\text { Stage } 2 \text { (regional): } \\
\text { Regional director of public health } \\
\text { investigates and decides whether } \\
\text { to refer complaint to stage } 3\end{array}$ & 56 & $29-92$ \\
\hline $\begin{array}{l}\text { Stage } 3 \text { (peer review): } \\
\text { JCC arranges appointment of } \\
\text { independent assessors }\end{array}$ & 33 & $27-45$ \\
\hline $\begin{array}{l}\text { Appointed assessors arrange to visit } \\
\text { district }\end{array}$ & 80 & $64-115$ \\
\hline $\begin{array}{l}\text { Assessors report findings of review } \\
\text { to the regional director }\end{array}$ & Same day & $0-6$ \\
\hline $\begin{array}{l}\text { Regional director reports assessors' } \\
\text { findings to district }\end{array}$ & 20 & $13-29$ \\
\hline All & 381 & $288-505$ \\
\hline
\end{tabular}


Table 2 Aspects of care which were subject of complaints investigations by peer review, according to whether patient was alive or had died

\begin{tabular}{lccc}
\hline Aspect of care & \multicolumn{3}{c}{ No (\%) complaints: } \\
\cline { 2 - 4 } & $\begin{array}{c}\text { Patient } \\
\text { alive }\end{array}$ & $\begin{array}{c}\text { Patient } \\
\text { dead }\end{array}$ & Total \\
\hline $\begin{array}{l}\text { Failure to initiate appropriate } \\
\quad \text { investigation or treatment }\end{array}$ & $20(17)$ & $12(13)$ & $32(15)$ \\
Communication & $31(26)$ & $28(30)$ & $59(27)$ \\
$\begin{array}{l}\text { Misapplication of clinical } \\
\quad \text { skills }\end{array}$ & $53(44)$ & $45(47)$ & $98(46)$ \\
Choice and decision sharing & $3(2)$ & $3(3)$ & $6(3)$ \\
Attitude and behaviour & $9(8)$ & $7(7)$ & $16(7)$ \\
Other & $4(3)$ & & $4(2)$ \\
\hline Total & 120 & 95 & 215 \\
\hline
\end{tabular}

sought and in which peer review was being arranged (table 1).

In most $(87 \%)$ cases complaints related to more than one aspect of the patient's care. Thus, for the 71 cases there was a total of 215 complaints about discrete aspects of patient care. Most of these complaints could be placed in one of five categories (table 2). Forty four per cent of all complaints related to the cases in which the patient who was the subject of the complaint had died. There was, however, no clear difference between the types of complaints which arose after the death of a patient and when the patient had not died.

Most complaints dealt with serious matters and some with very serious matters. For example, one complaint dealt with the clinical management of an 11 month old baby who had been discharged from an accident and emergency department twice despite reported symptoms of vomiting after a fall, who was subsequently found to have a subdural haematoma. Another complaint concerned a man in his 30s who had repeated consultations with a consultant for symptoms of neck pain and weight loss; he was treated with analgesics but, when finally admitted to hospital, he died precipitately of a previously unrecognised bronchogenic carcinoma. A third example was the case of a teenager who had been taken to the local accident and emergency department after collapsing in the street. $\mathrm{He}$ was discharged with a diagnosis of alcohol intoxication but had later to be re-admitted, when he was found to have a completed stroke.

Table 3 shows the proportion of complaints upheld by peer review for different categories of complaint. To test whether the differences in proportions were significant the "no" and

Table 3 Extent to which peer review found complaint justified according to nature of complaint. Figures are numbers

\begin{tabular}{|c|c|c|c|}
\hline \multirow[t]{2}{*}{ Aspect of care } & \multicolumn{3}{|c|}{ Complaint substantiated } \\
\hline & Yes & No & Uncertain \\
\hline Communication $(n=59)$ & 46 & 6 & 7 \\
\hline $\begin{array}{l}\text { Misapplication of clinical } \\
\text { skills }(\mathrm{n}=98)\end{array}$ & 20 & 67 & 11 \\
\hline $\begin{array}{l}\text { Failure to initiate appropriate } \\
\text { investigation or treatment } \\
(\mathrm{n}=32)\end{array}$ & 8 & 20 & 4 \\
\hline $\begin{array}{l}\text { Attitude and behaviour } \\
(n=16)\end{array}$ & 7 & 3 & 6 \\
\hline $\begin{array}{l}\text { Choice and decision sharing } \\
(\mathrm{n}=6)\end{array}$ & 4 & 1 & 1 \\
\hline Other $(n=4)$ & 1 & 3 & \\
\hline All $(n=215)$ & 86 & 100 & 29 \\
\hline
\end{tabular}

Table 4 Panel's assessment of quality of written responses to complainants. ${ }^{*}$ Figures are percentages

\begin{tabular}{|c|c|c|c|}
\hline Aspect of response & $\begin{array}{l}\text { Quite poor } \\
\text { or very } \\
\text { poor }\end{array}$ & $\begin{array}{l}\text { Neither } \\
\text { good nor } \\
\text { bad }\end{array}$ & $\begin{array}{l}\text { Quite good } \\
\text { very good }\end{array}$ \\
\hline How personalised $(n=65)$ & 14 & 19 & 67 \\
\hline How understandable $(n=47)$ & 17 & 24 & 59 \\
\hline How comprehensive $(n=47)$ & 25 & 20 & 55 \\
\hline $\begin{array}{l}\text { How sympathetic or } \\
\text { apologetic }(n=65)\end{array}$ & 31 & 23 & 46 \\
\hline $\begin{array}{l}\text { How reassuring of intent to } \\
\text { investigate }(\mathrm{n}=65)\end{array}$ & 22 & 20 & 58 \\
\hline $\begin{array}{l}\text { How reassuring of intent to } \\
\text { act on results of } \\
\text { investigation }(n=65)\end{array}$ & 44 & 25 & 31 \\
\hline How impartial $(n=65)$ & 17 & 38 & 45 \\
\hline $\begin{array}{l}\text { How much practical support } \\
\text { offered }(n=65)\end{array}$ & 40 & 36 & 24 \\
\hline $\begin{array}{l}\text { All aspects } \\
\text { (stages } 1 \text { and } 3 \text { of procedure) }\end{array}$ & $\begin{array}{c}26 \\
(n=47)\end{array}$ & 26 & 48 \\
\hline
\end{tabular}

"uncertain" outcomes for each category of complaint were combined and tested against the "yes" outcomes. Complaints classified as "other" complaints were omitted from the test. The proportion of complaints upheld varied significantly by category $\left(\chi^{2}=51.87\right.$, $\mathrm{df}=4 ; \mathrm{p}<0.001)$. Most of the variation was due to a higher proportion of complaints about communication being upheld than those concerning the application of clinical skills.

Two thirds of the sample of written responses to complainants were found by the panel to be quite good or very good in terms of how personalised they were, but lower proportions were judged to have reached this standard in relation to other aspects (table 4). The least satisfactory aspects of responses related to offers of practical support or reassurance that action would be taken on the results of an investigation. Many such letters ended abruptly - for example, "I think the conclusions of the independent consultants are self explanatory, but in the event of you requiring clarification on any of the matters referred to above, I should be most grateful if you would let me know." Others created the impression that patients were misguided in making the complaint - for example, "May I offer you our apologies for any misconceptions which you may have suffered." The use of highly technical explanations was particularly common - for example, "He was grossly oedematous and hypotensive despite inotropic support with the medications dopamine and dobutamine."

\section{Discussion}

People who are unhappy about the clinical care they receive in NHS hospitals face several options for expressing their dissatisfaction. They can raise their concerns informally with the health professional concerned, to have them settled by discussion and explanation; they can make a complaint formally to the hospital or health authority management, when it will be dealt with using the Hospital Complaints Procedure described, or they can take their complaint to law.

Complaints made by patients about their care represent an important opportunity to learn lessons about possible service failures, 
which can then be translated into improvements in service quality. An important factor in judging the quality of a health service should be how quickly and effectively complaints are resolved. Patients will wish to see their concerns taken seriously, their complaint investigated, a clear explanation given, and follow up action taken.

The number of formal complaints made by patients about the care they have received is small in relation to total episodes of treatment. ${ }^{10}$ Though this undoubtedly represents a generally high level of satisfaction with the public health care system in Britain, there is some evidence that people who wish to complain do not do so either because they do not know how or because they believe that it would be pointless to do so. ${ }^{11}$

The findings of this study show that patients who complain about the clinical aspects of their care and who wish their complaint to proceed through to a peer review investigation face a long drawn out process. A median duration of more than a year is surely unacceptable, though given the highly prescribed nature of the hospital complaints procedure, it is difficult to see where time could be consistently saved. Greater satisfactory resolution of complaints at local level would help, as would a decision to refer to the next stage being taken more quickly by the consultant or managers when resolution locally seems unlikely. As the peer review stage involves consultants being chosen from a national panel delays arising from identifying suitable candidates and finding a convenient date for their visit seem inevitable.

Thus, though improvements in administration could speed up the clinical complaints procedure, it will probably still take a fairly long time to reach a conclusion, given the structure of the present procedure. Moreover, the amount of management and professional time taken up by each complaint is substantial; in 1985 English regional medical officers estimated that 50 hours of staff time were deployed at regional level alone. ${ }^{12}$ In our experience the consultants performing the peer review spent an average of two working days on each case. The time spent locally is difficult to quantify but is usually also extensive. Furthermore, analysis of nine years' experience of the hospital complaints procedure in North West Thames region showed that less than half of complaints subject to peer review were resolved to the complainants' satisfaction. ${ }^{13}$ These factors and the longstanding criticism of the procedure ${ }^{7}$ suggest that it is in need of reform.

In bringing a complaint at all, patients face the dilemma of whether to criticise those who have cared for them and those to whom they may have to look for future care. ${ }^{14}$ The peer review process is undoubtedly a very thorough and conscientiously undertaken exercise, but does it fulfil the needs of those who complain ${ }^{15}$ - that is, for an explanation, an apology, and a reassurance that others will be spared a similar experience?

The Davies committee, which reported in
$1973,{ }^{16}$ criticised the health service at the time for having complaints mechanisms which were purely internal and based on general principles which were inconsistently applied. It recommended new arrangements which would involve lay participation in investigation of clinical complaints made by complainants who were dissatisfied with the action taken by a health authority. No substantive guidance was issued by the then Department of Health and Social Security, though prolonged consultation on the possible form of a new complaints procedure took place. In the late 1970 s the Select Committee on the Parliamentary Commissioner for Administration also reviewed existing arrangements and found them complicated, fragmented, and slow and concluded that they left many complainants dissatisfied. ${ }^{17}$ It recommended an extension of the role of the health services commissioner to cover complaints involving clinical judgement.

The evidence of the Joint Consultants Committee to this select committee rejected clearly any proposals to include clinical matters within a complaints procedure. Similarly, an editorial in the $B M \mathcal{F}$ at the time saw any such mechanism as a challenge to clinical judgement which would create a dangerous and unnecessary alternative to the judicial process of litigation. ${ }^{18}$ The procedure actually implemented did not adopt the proposals of either the Davies committee or the select committee, but, after negotiation with the medical profession, the Department of Health and Social Security implemented a complaints procedure which involved a peer review stage of investigation with no lay participation.

Our experience has been that complaints are not welcomed by health service managers or doctors. At best they tend to be greeted neutrally, but we have found that they are regarded by some doctors as an affront to their professional standing, and on occasions there has been talk of action being initiated by the doctor concerned on grounds of defamation. In one case such was the doctor's resentment of a complaint having been made that he sat with his back to the complainant during an entire meeting called to try to resolve the complaint.

The wording of the guidance on the conduct of the peer review process states that meetings between the complainants and the independent consultants should be "in the nature of a medical consultation." 6 The consultants are also described in parts of the guidance as "second opinions," and when they believe that clinical judgement was exercised responsibly they are asked to: "endeavour to resolve the complainants' anxieties." Meetings between the investigating consultants and the medical staff being complained against are described in guidance produced by the Joint Consultants Committee as "professional discussions" at which "no lawyer or third party should be present." 19 These features of the peer review process call into question whether the process is intended to be an objective 
investigation of the complaint and whether it will be perceived as such by the complainant. Morever, they perhaps further highlight the ambiguity about whether the procedure is perceived as addressing the patient's problem or addressing the needs of a problem patient. Our finding that professional peers were more likely to uphold complaints which alleged failures of communication or inappropriate behaviour than they were to accept allegations of errors in clinical judgement perhaps suggests that communication or behaviour is a more acceptable and less threatening aspect of professional practice on which to base a peer rebuke. Personal criticism can be difficult to accept; it has been suggested that doctors display an attitude which discourages complaints. $^{20,21}$

The lack of any systems allowing regular opportunities for staff to learn about failures in quality of care through discussing complaints, as well as the difficulty that doctors seem to have about accepting criticism relating to fundamental aspects of clinical practice, are both important obstacles in the overall complaints process within the health service. Far greater attention needs to be addressed to complaints in education programmes, which in itself would almost certainly promote the necessary change in attitude.

In this study the panel assessment of written responses to complainants highlighted other features of the complaints culture of the NHS. Generally, too many of the responses lacked the essential ingredients which would be regarded as mandatory in other sectors. In particular, the responses commonly failed to show a health authority's willingness to act on the results of the investigation or to offer practical advice or support to complainants.

It is easy to understand how the medical profession would not accept a clinical complaints procedure which entailed lay participation: it did not do so when the present procedure was being designed, and its view prevailed in the face of two major reports which advised government to the contrary. If, however, the Patient's Charter is to fulfil its aspiration of providing true accountability to consumers for this major public service then an acceptable complaints procedure will have to be rapid and responsive. It will also have to deal with all complaints, including those concerning clinical practice, in a way which clearly shows complete impartiality. In practice this will mean reviewing the structure of the hospital complaints procedure and reopening the contentious issue of lay involvement in the scrutiny of those complaints which are currently adjudicated only by doctors.

1 The citizen's charter. London: HMSO, 1991. (Cmnd 1599.)

2 Department of Health. The patient's charter. London: HMSO, 1991 .

3 Secretary of State for Scotland. The patient's charter: $a$ charter for health. Edinburgh: Scottish Office, 1991.

4 Department of Health and Social Security: Health service management: health service complaints procedure. London: DHSS, 1981. (HC(81)5.)

5 Hospital Complaints Procedure Act 1985. London: HMSO, 1985.

6 Department of Health and Social Security. Health service management: Hospital Complaints Procedure Act 1985. management: Hospital Complaints Proce
London: DHSS, 1988. (HC (88)37.)

7 Association of Community Health Councils for England and Wales. National Health Service complaints procedures. CHC health news briefing. London: ACHCEW, 1990.

8 Health Service Commissioner. Annual report for 1989-90. London: HMSO, 1990.

9 Mayo E. Hawthorne and the Western Electric Company: the social problem of an industrial civilisation. London: Routledge, 1949: 60-76.

10 Department of Health. Return of written complaints made by or on behalf of patients. London: Government Statistical Service, 1991 .

11 Prescott-Clarke P, Brooks T, Machray C. Focus on health care: surveying the public in four health districts. London: care: surveying the public in four health districts. London: Community Planning Research, 1988.

12 Scott JA. Complaints arising from the exercise of clinical judgement: a report by the English regional medical officers. Health Trends 1985;17:70-2

13 Geffen T. The complaints procedure. Health Trends 1990;

14 Clothier C. The patient's dilemma: the Rock Carling Fellowship 1987. London: Nuffield Provincial Hospitals Trust, 1987.

15 Bradley A. Consumer protection in health care: the need for information, explanation, and expert legal advice. Health and Law Letter 1990;10:6-9

16 Department of Health and Social Security and Welsh Office. Report of the committee on hospital complaints procedure (Davies committee). London: HMSO, 1973.

17 Select Committee on the Parliamentary Commissioner for Administration. Independent review of hospital complaints in Administration. Independent review of hospital complaints in
the National Health Service. London: HMSO, 1977. (First the National Health Service.

18 Challenging clinical judgement [editorial]. $B M \mathcal{F}$ 1977;ii:

19 Joint Consultants Committee. Note to consultants acting as a second opinion. London: BMA, 1989.

20 Simanowitz A. Standards, attitudes and accountability in the medical profession. Lancet 1985;ii:546-7.

21 Kaye C, MacManus T. Understanding complaints. Health Service fournal 1990; August 23:1254-5. 